\title{
Influence of Lead Substitution in Zinc Oxide Thin Films $†$
}

\author{
I. INIGO VALAN ${ }^{\mathrm{a}}$, S. RAJA ${ }^{\mathrm{b}}$, K. RAMAMURTHI ${ }^{\mathrm{c}}$, V. NARAYANAN ${ }^{\mathrm{d}}$ and A. STEPHEN ${ }^{\mathrm{a}}$ \\ ${ }^{\text {a } D e p a r t m e n t ~ o f ~ N u c l e a r ~ P h y s i c s, ~ U n i v e r s i t y ~ o f ~ M a d r a s, ~ G u i n d y ~ C a m p u s, ~ C h e n n a i, ~ I n d i a ~}$ \\ ${ }^{\mathrm{b}}$ Crystal Growth and Thin Films Lab, Bharathidasan University, Tiruchirappalli, India \\ ${ }^{c}$ Department of Physics and Nanotechnology, SRM University, Kattankulathur, India \\ ${ }^{\mathrm{d} D e p a r t m e n t ~ o f ~ I n o r g a n i c ~ C h e m i s t r y, ~ U n i v e r s i t y ~ o f ~ M a d r a s, ~ G u i n d y ~ C a m p u s, ~ C h e n n a i, ~ I n d i a ~}$ \\ stephen_arum@hotmail.com
}

Received 18 January 2013 / Accepted 15 February 2013

\begin{abstract}
Lead substituted zinc oxide thin films were deposited onto the glass substrates at $400{ }^{\circ} \mathrm{C}$ by spray pyrolysis technique. The influence of lead substitution concentration $(0-25$ wt. \%) on the structural, morphological and optical properties of zinc oxide thin films were studied. X-ray diffraction (XRD) analysis confirms that all the films have a typical hexagonal wurtzite structure having high preferred orientation along (002) crystallographic direction. The Scanning Electron Microscopy (SEM) reveals the deterioration of crystallinity as we increase the substitution percentage. The average transmittance is maximum for 25 wt. \% $\mathrm{ZnO}: \mathrm{Pb} \sim 93 \%$ in the visible region $(400-800 \mathrm{~nm})$. Optical band gap energy has a slight increase from $3.21 \mathrm{eV}$ to $3.36 \mathrm{eV}$.
\end{abstract}

Keywords: Thin films, Spray pyrolysis, Optical transmittance

\section{Introduction}

Zinc oxide $(\mathrm{ZnO})$ is highly interesting and widely studied transparent conducting oxide which has numerous applications. Some of its distinguishing properties are high transmittance range ${ }^{1}$, large exiton binding energy $(\sim 60 \mathrm{meV})^{2}$ and large band gap $(3.2 \mathrm{eV})^{3}$. The properties of $\mathrm{ZnO}$ thin film depend on the non-stoichiometry of the film resulting from the presence of oxygen vacancies and interstitial zinc. However stoichiometric zinc oxide is an insulator that crystallizes with wurtzite structure to form transparent needleshaped crystal ${ }^{4}$. The structure contains large voids which can easily accommodate interstitial atoms. Thus the substitution in $\mathrm{ZnO}$ can be easily achieved, because of this property. A lot of researches have been done by varying the dopant material in $\mathrm{ZnO}$ thin films. However literature review reveal that there are only a very few reports on lead $(\mathrm{Pb})$ substituted zinc oxide thin film. In this work the aim was to prepare $\mathrm{Pb}$ substituted zinc oxide thin films by low cost spray pyrolysis technique and to analyze the influence of $\mathrm{Pb}$ substitution on the structural, morphological and optical properties of $\mathrm{ZnO}$ thin films.

$\uparrow$ Presented to the National Conference on Chemistry Solutions at SRM University, India 


\section{Experimental}

A simple homemade spray pyrolysis experimental setup ${ }^{5}$ was employed to prepare $\mathrm{Pb}$ substituted $\mathrm{ZnO}$ thin films on ultrasonically cleaned microscopic glass substrate. $0.2 \mathrm{M}$ solution of zinc acetate was prepared in double distilled water and lead substitution was achieved from the source material of lead acetate. The $\mathrm{Pb}$ concentration was varied from 0 wt. $\%$ to 25 wt. $\%$ and dissolved in double distilled water along with Zinc acetate solution. Hereafter, the substitution concentration refers to the concentration of lead acetate in the spray solution. The solution was sprayed on the preheated glass substrates at $400{ }^{\circ} \mathrm{C}$. Spray parameters were kept constant. Dry air was used as the carrier gas.

Thickness of the films was measured by Filmetrics F20. The structural properties were analyzed by the XRD technique using a Philips X'Pert Pro X-Ray Diffraction System. The surface morphology was observed by using the ZEISS-XIGMA Field emission scanning electron microscope. The optical transmittance spectra were recorded in the range from 300 to $1100 \mathrm{~nm}$ with a Shimadzu (UV-1601) UV- Visible spectrometer.

\section{Results and Discussion}

Structural study

The XRD patterns were obtained for pure $\mathrm{ZnO}$ and $\mathrm{Pb}$ substituted $\mathrm{ZnO}$ thin films are shown in Figure 1. The XRD studies clearly reveal that all the films are polycrystalline in nature. The XRD pattern of the film shows that the film is crystallized in the wurtzite phase and for these samples, the diffraction peaks were compared with the hexagonal wurtzite $\mathrm{ZnO}$ (JCPDS No. 36-1451). It is perceptible from the Figure 1 that the unsubstituted films grow along the (002) and (101) directions. As the substitution is increased one of the predominant (101) peak disappears. From these data it is evident that as the substitution concentration is increased, the 002 peak become very strong, while the other peak almost vanishes.

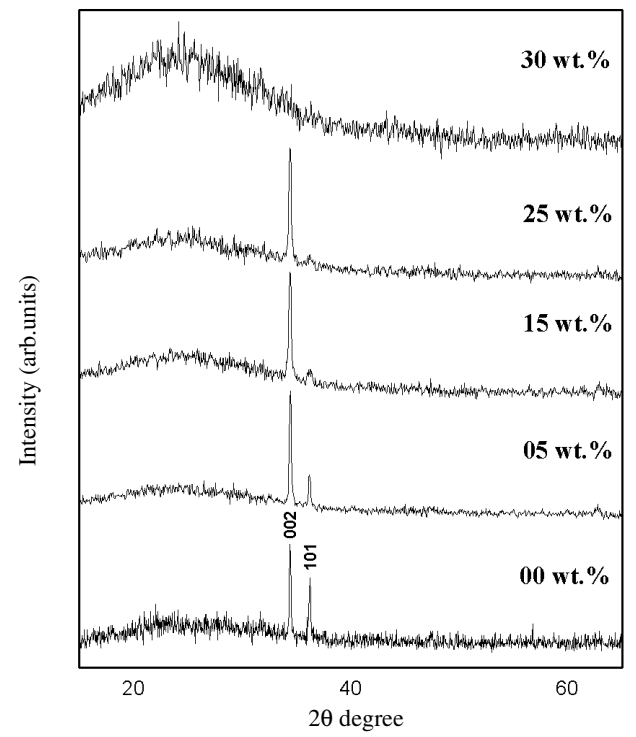

Figure 1. $\mathrm{X}$-Ray diffraction pattern of $\mathrm{ZnO}$ and $\mathrm{Pb}$ substituted $\mathrm{ZnO}$ films with different concentration 
It also shows that there is an increase in the surface migration of adatoms and thus it makes us attain films having highly preferred orientation. The crystalline quality of film is found to deteriorate with the increase of $\mathrm{Pb}$ substitution attains amorphous state for $30 \mathrm{wt}$ \% of $\mathrm{Pb}$ thereby reducing the intensity of $\mathrm{ZnO}\left(\begin{array}{lll}0 & 0 & 2\end{array}\right)$ plane. A similar behaviour has also been reported $^{6}$ for $\mathrm{Zr}$ doped $\mathrm{ZnO}$ films and found that interstitial inclusion of dopant atoms deteriorate the film structure and lead to the amorphization of film. Hence it is worth to conclude that increasing the $\mathrm{Pb}$ concentration in the solution increases the occupation of $\mathrm{Pb}^{4+}$ in the interstitial position rather than substitution of $\mathrm{Zn}^{2+}$ site which degrades the crystalline quality of the films and thus resulting amorphization for higher $\mathrm{Pb}$ substitution levels. The mean crystallite size calculated by using Sherrer's formula,

$$
\mathrm{L}=(0.9 \lambda) /(\beta \cos \theta)(\mathrm{nm})
$$

Where, $\lambda$ is the wavelength of the $X$-Rays used $(\lambda=1.5408 \AA), \beta$ is the full width at half maximum (FWHM) value in radians and $\theta$ is the Bragg's diffraction angle ${ }^{7}$. For $0-25 \mathrm{wt}$. $\% \mathrm{~Pb}$ substituted $\mathrm{ZnO}$ thin films the mean crystallite size are $46 \mathrm{~nm}, 38 \mathrm{~nm}, 32 \mathrm{~nm}$ and $33 \mathrm{~nm}$ respectively.

\section{Morphological Study}

The SEM images for the pure $\mathrm{ZnO}, 5$ wt. \%, 15 wt. \% and 25 wt. \% Pb substituted $\mathrm{ZnO}$ thin films sample are shown in Figure 2. When we increase the substitution percentage dark spots were observed in the images, these are the irregular arrangement or the unequal spread of the molecules which results in the amorphization of the film and the area of these dark spots increases as the substitution concentration is increased it shows the crystallinity of the film decreases as the substitution concentration is increased and it resemble the XRD pattern.
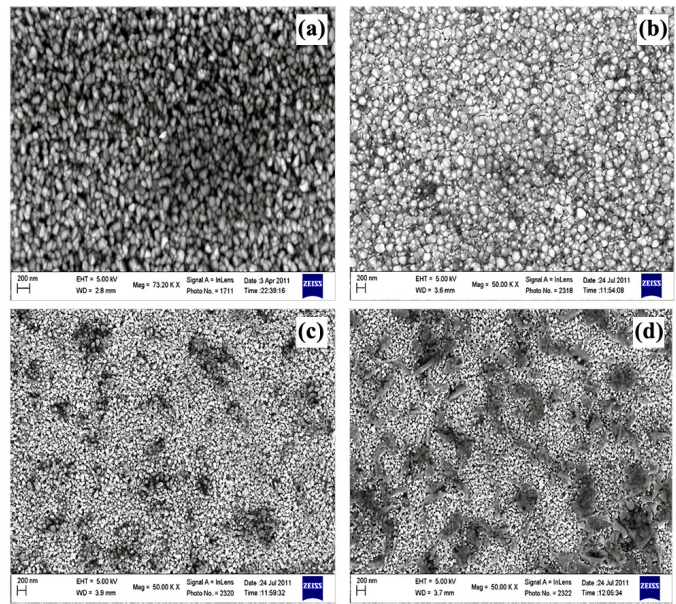

Figure 2. $\mathrm{SEM}$ images for pure $\mathrm{ZnO}$ (a), 5 wt. $\% \mathrm{~Pb}$ substituted $\mathrm{ZnO}$ (b), 15 wt. \% $\mathrm{Pb}$ substituted $\mathrm{ZnO}$ (c) and $25 \mathrm{wt}$. \% $\mathrm{Pb}$ substituted $\mathrm{ZnO}(\mathrm{d})$ respectively

\section{Optical study}

Figure 3 shows the transmittance spectra of the pure $\mathrm{ZnO}, 5$ wt. \%, 15 wt. \% and 25 wt. \% $\mathrm{Pb}$ substituted $\mathrm{ZnO}$ thin films samples. The transmittance spectra clearly reveal that the transmittance $\%$ of the film increases as the lead substitution concentration is increased in the $\mathrm{ZnO}$ thin films. It shows that the increase in lead concentration increases the transmittance 
of the film. The tabulation is made for determining the Average Visible Transmittance (AVT) is given in Table 1. The AVT in the wavelength ranging 400-800 $\mathrm{nm}$ for pure $\mathrm{ZnO}$ film is about $78 \%$ which nearly coincides with the results obtained by Gokulakrishnan et $a l^{8}$. The AVT increases gradually as the substitution concentration is increased from $00 \mathrm{wt} . \%$ (pure $\mathrm{ZnO}$ ) to $25 \mathrm{wt}$. \% $\mathrm{Pb}$ substitution in the $\mathrm{ZnO}$ thin films. The optical bandgap value $\mathrm{E}_{\mathrm{g}}$ can be obtained by extrapolating the linear region of "Tauc" plot of " $(\alpha h v)$ " drawn as the function of $h v$, is presented in Figure 4.

Table 1, Average visible transmittance as a function of substitution concentrations

\begin{tabular}{cc}
\hline $\begin{array}{c}\text { Substitution Concentration } \\
\text { Wt. \% }\end{array}$ & $\begin{array}{c}\text { Average visible Transmittance \% } \\
\text { AVT, 400-800 nm }\end{array}$ \\
\hline $00 \%$ & 77.85 \\
$05 \%$ & 85.95 \\
$15 \%$ & 87.02 \\
$25 \%$ & 93.32 \\
\hline
\end{tabular}

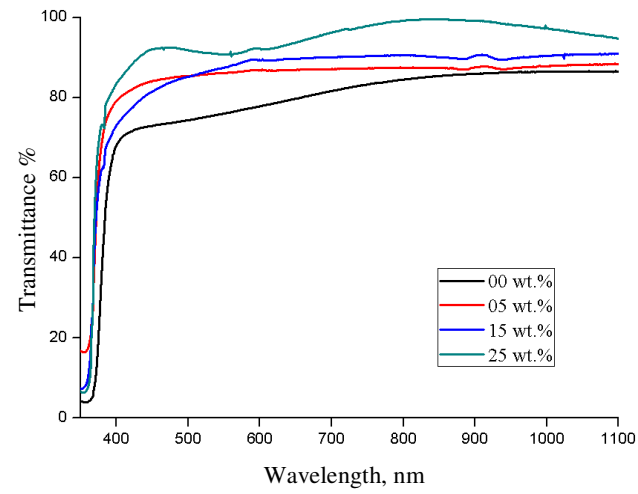

Figure 3. Transmittance spectra of $\mathrm{ZnO}: \mathrm{Pb}$ thin films as a function of wavelength for different $\mathrm{Pb}$ substitution concentration (wt. \%)

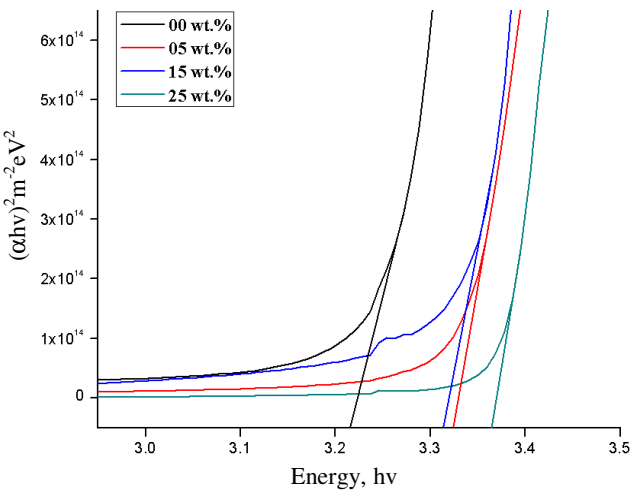

Figure 4. Plots of $(\alpha h v)^{2} v s$. hv of $\mathrm{ZnO}: \mathrm{Pb}$ films for various concentrations of Lead $(\mathrm{Pb})$

From the plot it is noted that the direct band gap for $\mathrm{ZnO}$ is found to be $3.27 \mathrm{eV}$ and as the substitution concentration is increased it is noted that the band gap value increases to $3.36 \mathrm{eV}$. This could be due to quantum confinement effect. According to quantum confinement theory, the energy band gap of a semiconductor increase with a decrease in crystallite size ${ }^{9}$. In our case, the crystallite size for pure $\mathrm{ZnO}$ films is $46 \mathrm{~nm}$ and decreases to $33 \mathrm{~nm}$ for $25 \mathrm{wt} \% \mathrm{~Pb}$ substituted $\mathrm{ZnO}$ film. Therefore the increase in bandgap energy is probably due to the quantum confinement effect.

\section{Conclusion}

Lead substituted zinc oxide thin films were prepared using the spray pyrolysis technique. The structural, optical and the morphological properties based on the substitution dependence for the films are studied. The XRD studies clearly reveal that the thin films prepared are polycrystalline in nature and the increase in substitution concentration makes us attain films having highly preferred orientation along (002) plane. The crystallinity of film is found to deteriorate with the increase of lead substitution concentration. The Scanning 
electron microscope images reveals that the crystalline quality of the film decreases as the substitution concentration is increased, which is similar to the results obtained from the XRD studies. The films were transparent in the wavelength range of $300-1100 \mathrm{~nm}$. The AVT $(400-800 \mathrm{~nm})$ of the film was $~ 93 \%$ for $25 \mathrm{wt} . \%$. The direct energy band gap value for pure $\mathrm{ZnO}$ is $3.27 \mathrm{eV}$ and increases to $3.36 \mathrm{eV}$ for $25 \mathrm{wt}$. \% $\mathrm{Pb}$ substituted $\mathrm{ZnO}$. Thus the properties of $\mathrm{ZnO}$ are influenced by the $\mathrm{Pb}$ substitution. They could therefore offer opportunities for further fundamental research and technological application.

\section{Acknowledgement}

The comments from V. Gokulakrishnan, P. Manimuthu and D. Manoj are gratefully acknowledged.

\section{References}

1. Nunes P, Fortunato E and Martins R, Thin Solid Films, 2001, 383, 277.

2. Fujimura N, Nishhara T, Goto S, Xua J and Ito T, J Cryst Growth., 1993, 130, 269.

3. $\quad$ Natsume Y and Sakata H, Thin Solid Films, 2000, 372, 30-36.

4. Azaroff L V, Introduction to solids (Mc Graw-Hill), New York, 1960, 371, 372.

5. Elangovan E and Ramamurthi K, J Optoelectron Adv Mater., 2003, 5, 45.

6. Gokulakrishnana V, Parthiban S, Jeganathan K and Ramamurthi K, Appl Surface Sci., 2011, 257, 9068- 9072.

7. Culity B D, Element of X - Ray Diffraction, Massachusetts, Adission-wesley, 1956.

8. Gokulakrishnanan V, Parthiban S, Jeganathan K and Ramamurthi K, Ferroelectrics 2011, 423, 126-134.

9. Srinivasan G, Rajendra Kumar R T and Kumar J, Opt Mater., 2007, 30(2), 314-317. 